\title{
Triangular model: Ultimate regime to enhance efficacy in Technical education
}

\author{
Dnyandeo Dattatraya Shinde ${ }^{1}$, Ramjee Prasad ${ }^{2}$ \\ ${ }^{1}$ Department of Mechanical Engineering, School of Engineering and Technology, Sandip University, Nashik, Maharashtra, India \\ ${ }^{2}$ Department of Business Development and Technology, Aarhus University, Herning, Denmark \\ 1ddshinde14@gmail.com \\ ramjee@btech.au.dk
}

\begin{abstract}
The technical education in India is on radar due to the poor employability of the graduates. The enrollment of students in higher technological education is drastically reducing year by year. A survey conducted to focus on this issue in engineering institutes in India. The purpose is to examine the lacunas in the technical education system. Based on the analysis, the triangular model is suggested, which is the ultimate model to increase productivity in the Indian higher technical education system. Herein, we have performed the survey-based analysis for $\sim 1800$ students from three technical institutes belonging to two different Universities in Maharashtra. In this model, we have chosen three vertexes with free to consign anywhere during trials on students. The vertex is a student, faculty, and lastly productive academic environment. Although, to increase the overall efficiency of student and teacher, we have initiated the triangular model using power law. However, the power-law has a generalized innovative capsule to improve the valid coefficient rating, which automatically increases the number of technical skills towards students.
\end{abstract}

\footnotetext{
Dnyandeo Dattatraya Shinde

Department of Mechanical Engineering,

School of Engineering and Technology, Sandip University,

Nashik, Maharashtra, India

ddshinde14@gmail.com
}

Keywords: Triangular models, Power-law, Sandip University, Employability, Higher technical education.

\section{Introduction}

Technical education plays a vital role and acts as the backbone for the development of the country. The quality of human beings might enhance the development of industrial efficacy and improve the lives of people. The first engineering college was developed in UP, in India, during the year 1847 with a Civil engineering branch; after that, from the year 1880 onwards, Electrical, Mechanical, and other departments progressively commenced in different institutes. Despite developments in technical education, the current scenario of employability and skills is not satisfactory; it shows the need to analyze and to rethink about Indian professional education. [1]

Various majors are taken by the Government of India to overcome the problem of employability. One of them is the "Make in India" project launched by the Indian Prime Minister to boost up start-up projects by budding entrepreneurs((Make in India 2014). Several skills-based training, seed funding, and facilities extended by the government to start new projects. The young mind has potential creative ideas that can use to increase the research also, which will help in increasing job opportunities. But, it seems to be lacking behind with some of the parameters discussed later in this paper. Also, during the golden era of more 
competitiveness, the quality, in terms of technical and skill set, required in graduates qualifying from engineering colleges, seems to be below level. The deficiency lies in quality, not quantity. According to a recent survey regarding employability by the Aspiring minds firm, only $19.11 \%$ of graduating engineering are employable [3][4] .

There are plenty of opportunities for improvements to be done in technical education for enhancing the quality of students for better employability. For analyzing the facts, initiatives should be taken and propose a model to find the root cause of poor employability in the technical stream from Indian Universities.

\section{Review of Literature}

The enrollment ratio in Technical Education is gradually decreasing every year, as per the All India Council of Technical Education (AICTE) report [5]. The stats show that as compared to 2015-16, there is a reduction of more than one lakh thirty thousand students as compared to intake for A.Y. 2016 - 17 followed by drop by more than fifty thousand student enrollment in next A.Y. [5].

Table 1 shows the enrollment of students in engineering branches.

Enrollment is just $51.17 \%$ of the intake, and as compared to it, only $32.8 \%$ of students were employed. It means nearly $67.2 \%$ of engineering students are without employment. As compared to the ratio of increase in new institutes and lateral entry in the intake, the placement options available are very less.[5] .

There is a need to brainstorm and act in the direction to increase the enrollment ratio of the students by making them employable. For the analysis, the feedback from the stakeholders Students, Staff, and Employers will help to identify the root causes of the problems. An attempt made to find out the root cause of the issues faced by the staff and students in technical institutes by Shinde et al.[6] . Sahu et al. attempted to identify the factors affecting the Effectiveness of Technical Education [7]. Accordingly, they suggested major factors governing effectiveness as Teaching Effectiveness, Infrastructure, Research and Development, and Extracurricular Activities. Thus, they recommended the mathematical model to enumerate it. Damayanti Sen describes the technical education system since independence; also, she shared majors taken by the government to improve it [8] . Many initiatives are made by the government of India to overcome the problem of employability.

Corrective majors are adopted by the Government of India, AICTE, and MHRD by revising the policies for improving the quality of technical education. Also, it is mandatory to follow the basic norms for infrastructure, quality of teachers and research, etc., through making it compulsory for the institutes to accredit themselves through various bodies like the National Board of Accreditation (NBA) and the National Assessment and Accreditation Council

Table 1. Engineering - Course v's Intake/Enrollment and placement for the AY 2016-17 (Source: AICTE) [5]

\begin{tabular}{|c|l|r|r|r|r|r|}
\hline $\begin{array}{c}\text { Sr } \\
\text { No. }\end{array}$ & \multicolumn{1}{|c|}{ Discipline } & Intake & Enrollment & $\begin{array}{c}\text { \% } \\
\text { enrollme } \\
\text { nt }\end{array}$ & $\begin{array}{c}\text { Place- } \\
\text { ment }\end{array}$ & \multicolumn{1}{c|}{$\begin{array}{c}\text { Pocement } \\
\text { Placement| }\end{array}$} \\
\hline 1 & Mechanical Engineering & 802484 & 422992 & 52.71 & 144363 & 34.1 \\
\hline 2 & Computer Science Engineering & 587244 & 320081 & 54.51 & 112712 & 35.2 \\
\hline 3 & $\begin{array}{l}\text { Electronics and Communication } \\
\text { Engineering }\end{array}$ & 556236 & 233825 & 42.04 & 100383 & 42.9 \\
\hline 4 & Electrical Engineering & 442296 & 215083 & 48.63 & 69120 & 32.1 \\
\hline 5 & Civil Engineering & 507664 & 261589 & 51.53 & 54104 & 20.7 \\
\hline 6 & Chemical Engineering & 36190 & 20883 & 57.7 & 6275 & 30 \\
\hline 7 & Textile Engineering & 12445 & 6358 & 51.09 & 2201 & 34.6 \\
\hline & & 2944559 & 1480811 & $\begin{array}{c}\text { Avg.: } \\
51.17\end{array}$ & 489158 & Avg.: 32.8 \\
\hline
\end{tabular}


(NAAC). However, the ground reality regarding following the norms laid down by governing bodies by the institutes is to be reviewed by students and parents. An initiative to enhances productivity in higher technical education to ensure that engineering graduates possess the necessary skill and quality to be employable. The survey conducted to investigate the problems of students.

Many of the researchers quoted for the improvement of higher technical education. Mohammed \& Elaine proposed a framework for measuring quality in engineering education. The formulated a result in terms of four dimensions: academic resources, attitude, competence, and content, along with 19 characteristics contributing to it[9]. Juan \& Evelio suggested a control system for engineering education, wherein improvement of the teaching-learning process suggested thorough reactive blended learning [10].

Jared \& Jung proposed a triangular prism model to analyze the online learning community through monitoring activities[10]. Zhang et al. discussed the use of simulation tools as an approach for real-time control of the education process, giving an example for chemical engineering[11] . Gattie et al. suggested a paradigm shift for problem-solving of engineers for which they proposed a Synthesis and Design Studio (SDS), a system based solution[12] .

Gupta describes the need for a change to be adopted by technical institutes and universities as per the expectations from various stakeholders. They elaborate on all the necessary parameters affecting the excellence of the institutes[13] . Arun Patil discussed different accreditation systems and analyzed their strength and weaknesses. There exist lot accreditation models that are complex, non-transparent, and challenging to apply, also having nonuniformity in them, thus proposed a model for a global accreditation system[14] .

\section{Methodology/Experimental Set-Up}

In this study, a solution proposed by survey-based analysis. The data collected through a survey of students from the technical institutes in Maharashtra, India, in September 2018. The students are from the engineering program. The program is of four years duration; the data collected from the second year to final year students in hard copy. The open-ended questionnaire was consisting of only one question.
Students were free to write their opinion. The institute chosen for analysis was:

1. Sandip Institute of Technology and Research Centre (SITRC), affiliated to the University of Pune.

2. Sandip Institute of Engineering and Management (SIEM), affiliated to the University of Pune.

3. School of Engineering and Technology (SOET), affiliated to Sandip University, Nashik.

From the above institutes, the number of responses received from students listed in Table 2 .

Table 2. Number of Responses from different institutes

\begin{tabular}{|l|c|c|}
\hline Sr. No & Institute & $\begin{array}{l}\text { No. of Students for } \\
\text { Feedback }\end{array}$ \\
\hline 1 & SITRC & 989 \\
\hline 2 & SIEM & 836 \\
\hline 3 & SUN & 408 \\
\hline \multicolumn{2}{|c|}{ Total Responses: } & $\mathbf{2 2 3 3}$ \\
\hline
\end{tabular}

Analysis of the Sample:

The survey conducted for a sample size of 2500 students. Out of this, the response of 2233 students received. It thus gives a response rate of $89.32 \%$. Few feedback sheets received were blank, few were incompletely solved and therefore rejected. The total completed sheets for analysis were 1800 . The completion rate is $80.61 \%$. The analysis shown is for 1800 students based on the survey sheets. Respondent answered the questionnaire with only one open-ended question - $\mathrm{a}$ few of the responses attached in Appendix -A.

Characteristics of the respondents:

The respondents are from Sandip Foundation's Engineering Institutes, Nashik. The data collected is characterized as per their semester/year of the course, branch, etc.

Analysis of Data:

The data analyzed by the author using statistical software Origin 8.0. The students' feedback is analyzed and classified into thirteen characteristics 
which are pointers to be focused on enhancing the quality of technical education:

1. Academic

2. Psychological

3. Finance-Fees/scholarships

4. Caste

5. Human values/employability.

6. Innovation/R\&D

7. Industrial Visit/ Workshop \& Seminar / Value Added Programs.

8. Professional Languages/Communication Skills

9. Sports

10. Time Management

11. Technical

12.Infrastructure

13.Business/ Entrepreneur
Out of the above parameters, the second point, i.e., psychological issues, are being addressed in authors, one of the papers presented in Global Wireless Summit 2018, Thailand. The paper addressed the solution through the implementation of Yoga. [4] .

\section{Result and Discussion}

The study has introduced the new concept to analyze the system of education, according to the students' feedback. Herein, we defined the power law that has directly influenced the rating of the students' problems faced in technical education. Academics have the significant responses noted, so a focus is on academics. A generalized formula based on power law is introduced to solve these academics and its essential parameters, which directly influence the students. The survey of more than two thousand students has forced to unravel this problem for technical education.

The output of the survey tabulated considering the thirteen points on which students focused on their feedback. The power law [15][16]' proposed to find a key element as academics, which has the highest responses of 642. Table 2 shows the $\log$ values of academics $(\mu)$ concerning students (A) / faculties (B), deviation point $(\mathrm{K})$ for all the 13 parameters.

Power Law: $\mu=\mathrm{KA}^{\mathrm{B}}$

Table 3. Power-law for the technical education system

\begin{tabular}{|c|l|r|r|r|r|r|}
\hline $\begin{array}{r}\text { Sr. } \\
\text { No. }\end{array}$ & $\begin{array}{r}\text { No. Of } \\
\text { responses }\end{array}$ & \multicolumn{4}{|c|}{$\log (\boldsymbol{\mu})=\log (\mathbf{K})+\mathbf{B}^{*} \log (\mathbf{A})$} \\
\hline 1 & Academics & 642 & 2.808 & 1802.437 & -0.301 & 1802.136 \\
\hline 2 & Industrial visits/Seminars/WS/ Events & 160 & 2.204 & 352.659 & -0.301 & 352.358 \\
\hline 3 & Innovation/ R \& D & 36 & 1.556 & 56.027 & -0.301 & 55.726 \\
\hline 4 & Professional Languages & 7 & 0.845 & 5.916 & -0.301 & 5.615 \\
\hline 5 & Counselling / Psychological & 10 & 1.000 & 10.000 & -0.301 & 9.699 \\
\hline 6 & Technical & 5 & 0.699 & 3.495 & -0.301 & 3.194 \\
\hline 7 & Sports & 7 & 0.845 & 5.916 & -0.301 & 5.615 \\
\hline 8 & Infrastructure & 10 & 1.000 & 10.000 & -0.301 & 9.699 \\
\hline 9 & Time Management & 25 & 1.398 & 34.949 & -0.301 & 34.647 \\
\hline 10 & Industry / Site Sector & 5 & 0.699 & 3.495 & -0.301 & 3.194 \\
\hline 11 & Caste & 7 & 0.845 & 5.916 & -0.301 & 5.615 \\
\hline 12 & Finance & 23 & 1.362 & 31.320 & -0.301 & 31.019 \\
\hline 13 & Business / Entrepreneur & 5 & 0.699 & 3.495 & -0.301 & 3.194 \\
\hline
\end{tabular}


Herein, power law has been transferred to straight lines so that it is easy to calculate different parameters.

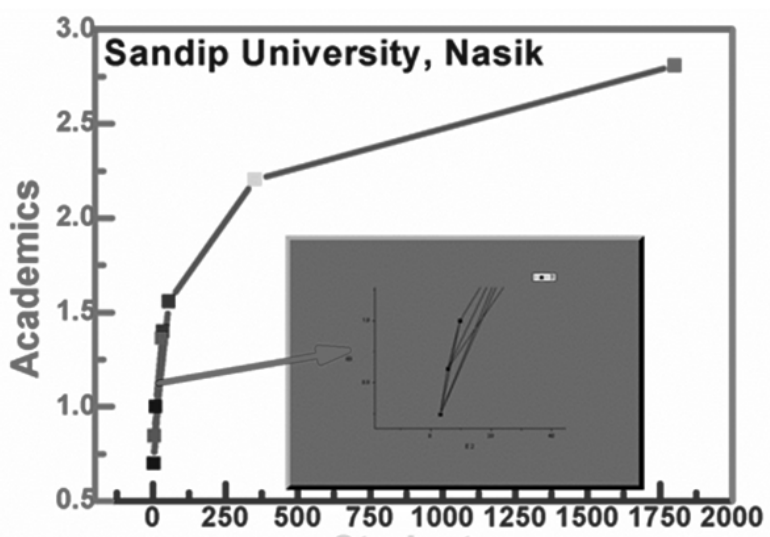

Fig. 1: Non-linear curve indicates three vertices which obey a power law

In the present study, we have proposed the model for the three cases - Academics, Students, and Faculty, to enhance the productivity of the three vertexes in the triangular model. During the triangular model, academics come on the first property, which sustains the educational institute. As we move further, due to the rotation of the axis, it causes students to arrive at the topmost position in the vertex of the triangle, as shown in Fig. 2.

At this, we consider, to propagate further to improve the system in technical education, our group has proposed a power law to solve this complex problem.
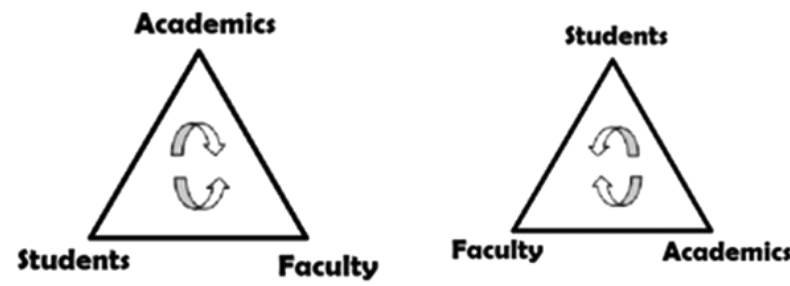

Fig. 2: Triangular model in terms of the education system

Based on the model, we have a plot of the logarithmic curve in terms of straight lines, which predicts the academic requirements in the students, with the help of software Origin 8.0. In the initial conditions, to 500 students, academic requirements follow a directly proportional power law. As we move on the further study, academic requirements between three vertices increase up to 2.7 ; it believes that the academic curriculum is very much useful to the students of the current batch of the Sandip University, Nasik. Herein, our group has used a triangular model, which rotates itself with three degrees of freedom in today's era of the education system, i.e., faculty, students, and academics.

Outcome-based education implemented in SOET, Sandip University, for improvement of academic performance. On this basis, we have introduced productive efficiency $(\eta)$ of the students using power law:-

$\eta=(x 1+x 2+x 3) * 100 / 1800$

Where,

$\mathrm{x} 1=$ coordinate of one vertex in triangular model,

$\mathrm{x} 2=$ coordinate of the second vertex in triangular model, \&

$\mathrm{x} 3=$ coordinate of the third vertex in triangular model

$\eta=36-45 \%$

It indicates that the outcome-based educations productive efficiency has increased from $36.8 \%$ in the Analyst Education system.

\section{Conclusions}

Based on the rotational degree of the triangular model, we have proposed the power-law, which might be useful in deciding three critical factors in the education system - Academic, Student \& Faculty. However, in the graph, some values are coming in a zig-zag pattern. It indicates a lack of coordination with the three degrees of freedom during the analysis of Sandip University students. Also, it does follow a logarithmic curve, which is indicated in terms of the non-linear coordinate system, to merge the gap of 1800 students with poor and sound in the University patterns, and marks are given accordingly with the concepts of the outcome-based education system. Once the Academic is improved, it will result in better employability of the students.

\section{References}

[1] A. Report, "Depart of Higher Education, Ministry of Human Resource Development, Govt. of India," 2017.

[2] "www.makeinindia.com, Make in India," Ministry of Finance, 2014. 
[3] A. Minds, "National Employability Report, Engineers Annual Report 2019," 2019.

[4] Shinde Dnyandeo, M. Srivastava, and R. Prasad, "An Initiative to Enhance Productivity in Higher Education ( Technical ) using Yoga, which interconnects human mind and body," in 2018 Global Wireless Summit (GWS), Chiang Rai, Thailand, 2018, no. November 2018, pp. 190193.

[5] AICTE, "All India Council of Technical Education, Annual Report \& Audited Accounts 2015-16," 2017.

[6] Shinde Dnyandeo Dattatraya, S. Ahirrao, and R. Prasad, "Fishbone Diagram: Application to Identify the Root Causes of Student-Staff Problems in Technical Education," Wirel. Pers. Commun., vol. 100, no. 2, pp. 653-6645, 2018.

[7] A. Sahu, R. L. Shrivastava, and R. R. Shrivastava, "Key Factors Affecting The Effectiveness of Technical Education-An Indian Perspective," Proc. World Congr. Eng., vol. II, pp. 2-6, 2008.

[8] D. Sen, "International Journal of Multidisciplinary Education and Research Higher education policies: The Indian experience since independence," Int. J. Multidiscip. Educ. Res., vol. 1, no. 10, pp. 15-21, 2016.

[9] M. S. Owlia and E. M. Aspinwall, "A framework for measuring quality in engineering education," Total Qual. Manag., vol. 9, no. 6, pp. 501-518, 1998.

[10] J. A. Méndez and E. J. González, "A control system proposal for engineering education," Comput. Educ., vol. 68, pp. 266-274, 2013.

[11] Y. Zhang, M. T. Munir, W. Yu, and B. R. Young, "A real-time approach to process control education with an open-ended simulation tool," Educ. Chem. Eng., vol. 8, no. 3, pp. e105-e112, 2013.

[12] D. K. Gattie, N. N. . Kellam; J. R. Schramski; and J. Walther, "Engineering education as a complex system," Eur. J. Eng. Educ., vol. 36, no. 6, pp. 521-535, 2011
[13] B. L. Gupta and M. Gupta, "Academic Excellence in Technical Institutions," Issues Ideas Educ., vol. 1, no. 1, pp. 23-42, 2013.

[14] A. Patil and G. Codner, "Accreditation of engineering education: review, observations, and proposal for global accreditation," Eur. J. Eng. Educ., vol. 32, no. 6, pp. 639-651, 2007.

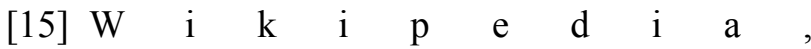
"https://en.wikipedia.org/wiki/Power_law.".

[16] Y. Chen, "Power-law distributions based on exponential distributions?: Latent scaling, spurious Zipf's law, and fractal rabbits," Fractals Complex Geom. Patterns, Scaling Nat. Soc., vol. 23, no. 2, pp. 1-23, 2015.

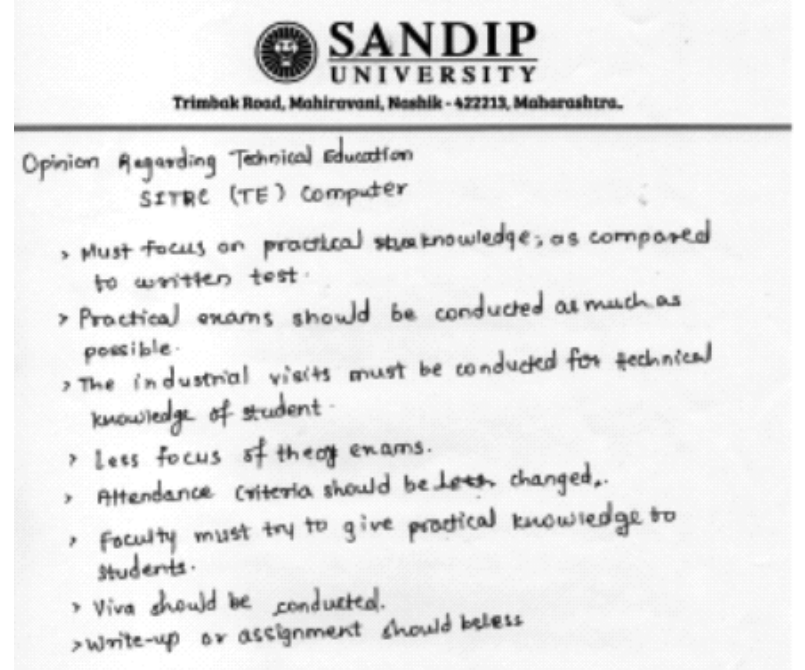

